\title{
Fast charging stations for electric vehicles infrastructure
}

\author{
J. Borges ${ }^{1,3}$, C. S. Ioakimidis ${ }^{1,2}$ \& P. Ferrão ${ }^{1,2}$ \\ ${ }^{I}$ MIT|Portugal Program, Sustainable Energy Systems, Portugal \\ ${ }^{2} I N+$, Instituto Superior Técnico, Lisbon, Portugal \\ ${ }^{3}$ noLimits Consulting, Lisbon, Portugal
}

\begin{abstract}
The growing problem of climate change associated with high oil prices is increasing the interest and research on electric vehicles (EVs). EVs due to the storage capacity provided by the batteries can supply or store electricity when parked. At the same time the electric power grid and light vehicle fleet can be exceptionally complementary as systems for managing energy and power. In the case of isolated systems, such as the islands, the introduction of EVs could be very beneficial not only environmentally since they are competing directly with the internal combustion engine vehicles but also economically and in the energy mixture of the local system. But to drive these vehicles, it is necessary to have a charged battery. To assure this, an infrastructure system is needed, connected to the grid, that can provide a parking charge (so that EVs can charge at homes, offices, public parks, etc) and an ongoing charge (so that travellers can refill their EV power in a fast process, like a fast charging station or a switching battery facility). Fast charging is mainly for commercial and public applications and is intended to perform similarly to a commercial gasoline service station, aiming to achieve a 50\% charge in an EV's battery in 10 to 15 minutes. This work studies and evaluates the fast charging infrastructure and the developed methodology that can optimize the station profit and still provide a charging price lower than the fuel price at the gas stations. The model simulates the fast charging price for drivers at the station and compares with the house night charging and with the internal combustion engine (ICE) fuel (diesel and gasoline) at the gas stations, for the Portuguese case.
\end{abstract}

Keywords: electric vehicles, fast charging, EV infrastructure, charging price. 


\section{Introduction}

The growing problem of climate change associated with high oil prices is increasing the interest and research on electric vehicles (EVs). Different kinds of EVs are being developed and promoted, such as the battery EV, fuel cell vehicle or plug-in hybrid (electric motor with onboard battery and a traditional internal combustion engine) [1]. EVs of today are evolving into a reliable and marketable product. The evolution of vehicle technology is ever going forward and the latest developments make electric traction technology suitable for virtually any application in meeting the most critical of today's transportation challenges. The technological maturation of EVs will lead to a progressive substitution of internal combustion engine (ICE) vehicles in the medium-long term, due to the environmental benefits that can be achieved as a consequence of lower overall $\mathrm{CO}_{2}$ emissions and greater overall energy efficiency. In this way, EVs may also contribute to the optimization of the electric power systems, if they can play a role not only as electric power consumers, when recharging batteries, but also as small distributed energy storage, under pre-defined conditions when they are grid connected. EVs, due to the storage capacity provided by the batteries, can generate or store electricity when parked. So if the car can be used, during the time it is parked, for some value generating activity, it could make EVs much more economically attractive.

But to drive an EV, it is necessary to have a charged battery. To ensure this, an infrastructure system is needed, connected to the grid, that can provide charging points when the vehicle is parked (so that EVs can charge at homes, offices, public parks, etc) and when it needs a quick charge (so that long distance travellers can refill their EV power in a fast process, like a fast charging station or a switching battery facility).

Apart from the pollution advantages, the EVs and their infrastructure implementation are expected to generate new business opportunities, from the new possibility of car owners to sell stored energy and the increase of market players in a more competitive market to the creation of changing batteries facilities or fast charging stations.

It is commonly assumed that EVs will charge at homes at night, but what will happen for those who do not have a garage? What if a driver intends to travel a longer distance than the one charge range of his EV? Are fast charging stations viable infrastructures and is the fast charging price competitive when compared to fuel prices at gas stations?

This work studies and evaluates the fast charging infrastructure and the developed methodology that can optimize the Station Profit and still provide a charging price lower that the fuel price at the gas stations. The model simulates the fast charging price for drivers at the station and compare with the house night charging and with the internal combustion engine (ICE) fuel (diesel and gasoline) at the gas stations, for the Portuguese case. 


\section{Charging infrastructure}

EVs do not have the backup of a gasoline engine and an infrastructure of petrol stations for longer distances. If we can only charge them at night, the range of our vehicles would be limited to nearly $160 \mathrm{~km}$ (100 miles) per day (on a typical EV, e.g. Nissan Leaf ), or only half of that when the cars are driven at high speed [2]. For EVs to succeed, it is important to implement a charging infrastructure that responds to the needs of EV driver's and allow everyone the so essential mobility.

The charging infrastructure can be seen as the energy and economic transaction needed to support the viability of EVs (Fig 1).

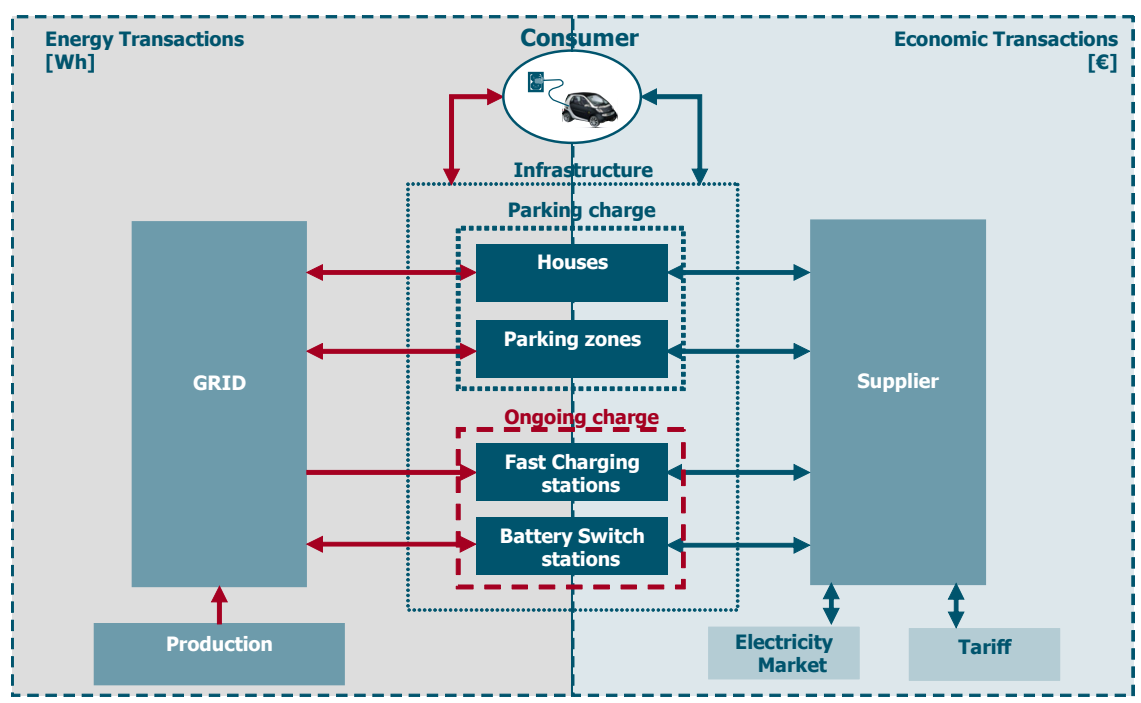

Figure 1: Electric vehicle's infrastructure diagram.

The infrastructure can be divided into parking charge and ongoing charge. The focus of this study is mainly on fast charging station as a part of the ongoing charge process.

\subsection{Parking charge}

Parking charge can be defined as the charging process that happens when the EV is parked for some time, like at houses, offices, parking lots, shopping centers, etc. In these types of places, it is expected to be used a normal outlet (ex: 230 VAC in Europe or 110 VAC in the USA).

It is expected that a big part of EVs will be charged at homes and mainly at night. But not everybody has a garage or a dedicated place to charge an EV. This means probably that an infrastructure of outlets is also necessary along the curbs of cities and towns, parking lots, shopping centers, offices, etc, to give the possibility for everybody to charge their EV while parked. 


\subsection{Ongoing charge}

An ongoing charge can be defined as the fast process to charge EVs that intend to support charging on long distances journeys and provides a similar function as the gas stations. There are, for now, two main possible infrastructures that can perform this objective: battery switch stations and fast charging stations.

\subsubsection{Fast charging stations}

Fast charging stations are one possible way to charge an EV in a fast process and when the driver is not at home and has not arrived to the destination.

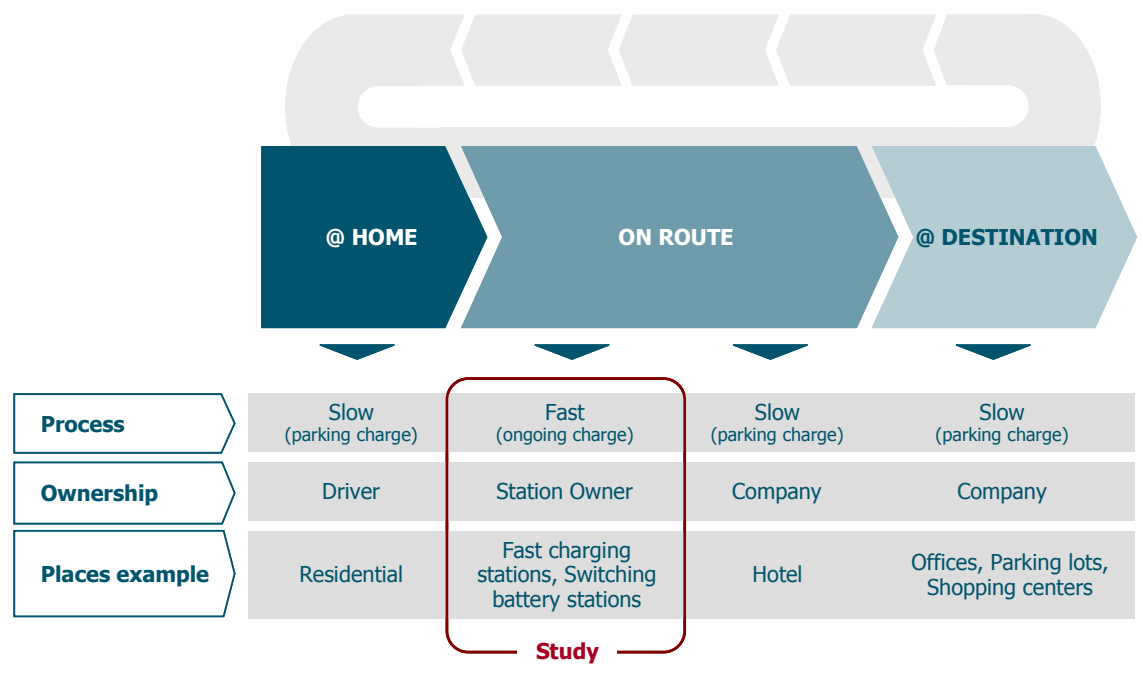

Figure 2: Electric vehicle's charging processes.

Fast charging is for commercial and public applications and is intended to perform similar to a commercial gasoline service station. It typically uses an offboard charge system serviced by a $480-\mathrm{VAC}$, three-phase circuit. In practice, equipment sizes can vary from 50 to $150 \mathrm{~kW}$, and if battery EVs achieved a $50 \%$ charge in 10 to 15 minutes, this is considered to meet the intent of fast charging [3].

But still 15 minutes is a while to wait compared to filling up at a gas station in less than five. There are some ideas suggesting that companies like coffee shops or shopping centers should get into fast charging, creating charge stations in their parking lots so that people can charge up while using their services [4]. So it appears that the opportunity exists for somebody to enter the fast-charging business, or partner with a fast-charging provider. But what kind of important service would be offered that could take anywhere from 10 to 30 minutes? And what about fast charging at gas stations? The infrastructure is there but safety has to be assured regarding the proximity of highly combustible fuel and highvoltage. It is also unclear whether fast charging stations would need to be 
carefully attended during the charging process, to prevent vehicles from staying hooked up to the chargers once they are fully recharged.

So placing some fast chargers along freeways accompanied with conventional fuelling station services such as restrooms and food services would greatly improve the utility of limited range EVs, with minimal impact to the driver when compared to using a petroleum fuelled car for those long trips.

\section{Methodology}

For fast charging stations to succeed in the market they must be able to be a profitable business for investors and to offer a competitive charging price to clients.

The model uses the tools MatLab and Excel and analyses the economic viability of a fast charging station over a period of 20 years, simulating a fast charging price for drivers that optimizes the station's profits and can still be competitive when compared to fuel prices at gas stations.

On an annual basis, the profit of the fast charging station can be calculated as the annual revenues minus the annual costs (eqn (1))

$$
\text { Profit }_{\text {annual }}=\text { Revenues }_{\text {annual }}-\text { Costs }_{\text {annual }}
$$

where Costs are composed by CAPEX (Capital Expenditures = Investments) and OPEX (Operational Expenditures = Operational Costs).

The most significant cost of OPEX is the energy cost. Starting at an hourly basis, the hourly energy cost of fast charging is (eqn 2):

$$
\text { EnergyCost }(h)=\text { Energy }_{\text {required }}(h) \cdot \text { price }_{\text {electricity }}(h)
$$

where the Energy required can be written as eqn (3):

$$
\text { Energy }_{\text {required }}(h)=D(h) \cdot \sum_{i=1}^{\text {ntime }_{c h}}\left(\text { perctime }_{c h}(i) \cdot \text { time }_{c h}(i)\right) \cdot \operatorname{Pot}_{c h}
$$

being:

- $D(h)-E V$ 's demand function of hour

- time $_{\text {ch }}$ - charging time (considered: 5, 10, 15 minutes)

- perctime $_{c h}$ - percentage of EVs per hour for each charging time

- Pot $_{c h}$ - Charger Power

The most significant revenue of the fast charging station is the charging revenue. The hourly charging revenue can be calculated as (eqn (4)):

$$
\text { ChRevenue }(h)=\text { Energy }_{\text {supplied }}(h) \cdot \text { price }_{\text {charging }}(h)
$$


where:

$$
\text { Energy }_{\text {supplied }}=\text { Energy }_{\text {required }} \cdot \eta
$$

being:

- $\quad \eta$ - fast charger efficiency

Having the annual cash flows of the fast charging station, an NPV (Net Present Value) approach will be used to determine the economic viability and the consequent fast charging price for drivers, over a 20 -year period.

The NPV is the difference between the present value of cash inflows and the present value of cash outflows and can be calculated with the eqn (6):

$$
N P V=\sum_{t=1}^{T} \frac{C_{t}}{(1+r)^{t}}-C_{0}
$$

where:

- $C_{t}-$ Cash Flow in the year $\mathrm{t}$

- $C_{0}-$ Investment

- $r-$ Discount rate

- $t-$ Year

\subsection{Investment (CAPEX)}

To build a fast charging station from the start, the first investments to be made are the place and the station infrastructures. The land can be bought, rented or loaned as well as the infrastructure itself and it is a cost that should be considered. But in the beginning, these kinds of stations are more likely to appear where there are already some infrastructures, like fuel stations or integrated with some businesses that can provide services during the fast charging time, like coffee shops, drive in restaurants, etc.

The fast chargers' cost is another important investment. This cost depends on the equipment power which was assumed to be $50 \mathrm{~kW}$.

Another investment necessary is the electric grid connection. As fast chargers power were assumed to be $50 \mathrm{~kW}$ and assuming that the station will have at least two chargers (at the beginning), the power required to the grid easily exceeds $100 \mathrm{kVA}$. Over this amount of power needed, the supplier usually suggests a medium voltage connection to the grid, which leaves the low voltage transformation costs to the client. These costs include a secondary substation and the necessary electrical equipment.

\subsection{Operational costs (OPEX)}

The main operation cost of a fast Charging Station is the cost of electricity. As a business with a relatively high consumption, a fast charging station is expected 
to be a medium voltage client, and may buy electricity in the regulated market, through the tariff, or in the electricity market.

The Portuguese regulated medium voltage tariff has three options: short, medium or long usages and the monthly cost is the sum of the power charges (contracted power and peak hours charge), active and reactive energy price and a fixed monthly term. In the liberalized market, a client in Portugal may buy electricity in the MIBEL (Iberian Electricity Market), directly if it is a qualified agent or through an electricity supplier which acts as an intermediary. The final client price is the sum of the MIBEL electricity price, the network access price and the supplier margin. For this study it is considered that the station will buy electricity at the medium voltage Portuguese tariff.

The maintenance costs of the station are also included in the OPEX.

\subsection{Revenues}

The main revenues of a fast charging station come from the charging price. To establish a price that can make the business profitable and at the same time be competitive is in fact the main focus of this study.

\section{Results}

Over the 20-year period of analysis, the economic model returned with a 219 thousand $€$ of profits (17\% of revenues) (Fig 3 ).

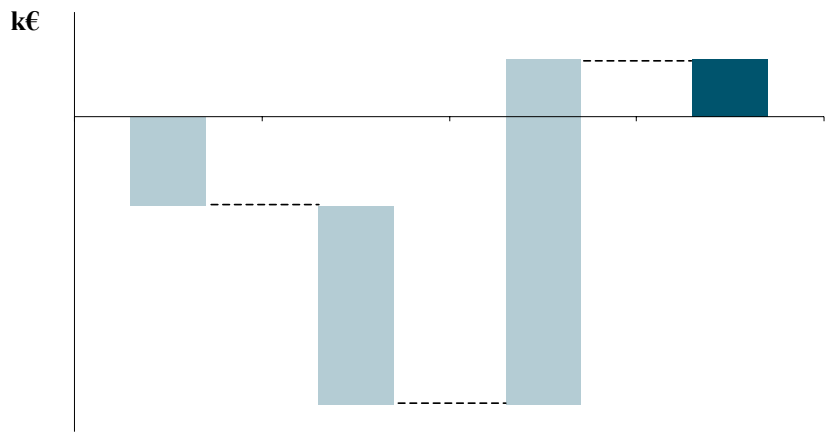

Figure 3: $\quad$ Fast charging station net present value.

To achieve this NPV result, the model simulated the fast charging price at the station, resulting in $0,171 € / \mathrm{kWh}$.

Since the night charging at home is expected to be the main charging process of EVs, it is important to compare prices with the fast charging at the station (table 1). For this comparison, it is assumed that the home infrastructure relies on a 230 VAC single phase outlet with a 3,45 kVA of maximum power and the charging period will occur at night, during the off peak hours, at a price of 0,066 $€ / \mathrm{kWh}$ corresponding to the bi-hourly low voltage Portuguese tariff [5]. The 
EV chosen for this comparison is the Nissan Leaf which has a lithium-ion battery with a total capacity of $24 \mathrm{kWh}$ and a driving range of $160 \mathrm{~km}$ [6]. Since the Renault-Nissan alliance has established a partnership with the Portuguese government, it is expected that the Nissan Leaf will be one of the first EVs entering the Portuguese market.

Table 1: $\quad$ Fast charging and home charging comparison.

\begin{tabular}{|c|c|c|c|}
\cline { 3 - 4 } \multicolumn{1}{c|}{} & \multicolumn{2}{c|}{ Charging Infrastructure } \\
\cline { 2 - 4 } \multicolumn{1}{c|}{} & Units & $\begin{array}{c}\text { Home } \\
\text { (at night) }\end{array}$ & $\begin{array}{c}\text { Fast Charging } \\
\text { Station (FCS) }\end{array}$ \\
\hline EV consumption & $\mathrm{kWh} / \mathrm{km}$ & \multicolumn{2}{c|}{0,150} \\
\hline Charging Price & $€ / \mathrm{kWh}$ & 0,066 & 0,176 \\
\hline Price per $\mathrm{km}$ & $€ / \mathrm{km}$ & 0,010 & 0,026 \\
\hline Charging time & hours & $6,96(\sim 7 \mathrm{~h})$ & $0,48(\sim 30 \mathrm{~min})$ \\
\hline Cost per charge & $€$ & 1,59 & 4,24 \\
\hline
\end{tabular}

Table 1 shows that the fast charging price is 2,7 times higher than charging at home during the night. To fully charge the EV, the driver can spend 1,59€ over 7 hours at home during the night or spend $4,24 €$ in less than 30 minutes at a fast charging station.

As fast charging station appear to be an alternative when drivers need an extra driving range, a 10 minute charge allows this EV driver to travel more than 56 $\mathrm{km}$ spending less than $1,5 €$.

The comparison between the charging price of an EV at the two previous EV infrastructures and the refuelling of diesel and gasoline of two similar ICE vehicles at gas stations is presented in table 2. The ICE vehicles used for comparison were chosen for the similarities with the Nissan Leaf and are Renault Mégane Berlina Dynamique TCe $130 \mathrm{cv}\left(1400 \mathrm{~cm}^{3}\right)$ gasoline with an average mix consumption of 6,6 liters $/ 100 \mathrm{~km}$ and the Renault Mégane Berlina $1.5 \mathrm{dCi}$ $85 \mathrm{cv} \mathrm{ECO}{ }^{2}$ diesel with an average mix consumption of 4,4 liters $/ 100 \mathrm{~km}$ [7].

Table 2: $\quad$ Price comparison between EV charging and ICE vehicle refuel.

\begin{tabular}{|c|c|c|c|c|}
\hline & \multicolumn{2}{|c|}{ EV charging } & \multicolumn{2}{|c|}{ ICE fuel at Gas Station } \\
\hline & $\begin{array}{l}\text { Home } \\
\text { (at night) }\end{array}$ & FCS & Diesel & Gasoline \\
\hline \multirow[t]{2}{*}{ Vehicle consumption } & 0,150 & 0,150 & 0,044 & 0,066 \\
\hline & \multicolumn{2}{|c|}{$\mathrm{kWh} / \mathrm{km}$} & \multicolumn{2}{|c|}{$\mathrm{l} / \mathrm{km}$} \\
\hline \multirow[t]{2}{*}{ Charging/Fuel Price } & 0,066 & 0,176 & 1,060 & 1,305 \\
\hline & \multicolumn{2}{|c|}{$€ / k W h$} & \multicolumn{2}{|c|}{$\epsilon / l$} \\
\hline \multirow[t]{2}{*}{ Price per $\mathrm{km}$} & 0,010 & 0,026 & 0,047 & 0,086 \\
\hline & \multicolumn{4}{|c|}{$\epsilon / \mathrm{km}$} \\
\hline $40 \mathrm{~km}$ travel cost & $0,40 €$ & $1,06 €$ & $1,87 €$ & $3,45 €$ \\
\hline
\end{tabular}


With the table 2 results it is possible to show that fast charging an EV is $43 \%$ cheaper than refuelling a diesel ICE vehicle and 70\% less expensive than refuelling a gasoline ICE vehicle. Assuming an average driving range per day of $40 \mathrm{~km}$, a driver would be able to fast charge his EV with just over $1 €$.

\section{Conclusions}

This work studies and evaluates the fast charging infrastructure and the developed methodology that can optimize the station profit while still providing a charging price lower that the fuel price at gas stations. The model simulates the fast charging price for drivers at the station and compares with the house night charging and with the ICE fuel (diesel and gasoline) at gas stations, for the Portuguese case.

Fast charging stations are one possible way to charge an EV in a fast process and when the driver is not at home and has not arrived at the destination. These stations are part of the EV ongoing charge process and intend to perform similarly to a commercial gasoline service station. If EVs achieved a 50\% charge in 10 to 15 minutes, this is considered to meet the intent of fast charging.

The model simulated a fast charging price at the station of $0,176 € / \mathrm{kWh}$, which provides $17 \%$ profits (NPV over a 20 year period) for station stakeholders. This price is almost 3 times higher than charging the EV at home during the night (off peak hours) but it is $43 \%$ lower than refuelling a diesel ICE vehicle and $70 \%$ lower than a gasoline ICE vehicle.

Fast charging stations appear to be an opportunity for new profitable businesses that can play an important role in the EV's infrastructure, supporting mainly long distance travellers and supplying a fast alternative to the several hours' charging at home.

\section{Acknowledgement}

The authors would like to thank the FCT MIT-Portugal program for the financial support for the work reported in this paper and performed under the project 'Power demand estimation and power system impacts resulting of fleet penetration of electric/plug-in vehicles' (FCT MIT-Pt/SES- GI/ 008/2008).

\section{References}

[1] C.S. Ioakimidis, C.Camus, P.C.Ferrão, "The Introduction and use of Plug-in Hybrid Electric Vehicles in the energy and fleet mixture in the island of São Miguel", paper in submission General of Power Sources.

[2] "Who killed the electric grid? Fast-charging electric cars", March 10, 2009.

[3] "Plug-in Hybrid Electric Vehicle Charging Infrastructure Review", U.S. Department of Energy Vehicle Technologies Program, K.Morrow, D.Karner, J.Francfort, November 2008. 
[4] "Electric Car Charge Stations: The Next Third Space?", The big money, August 7 2009; http://www.thebigmoney.com/blogs/shifting-gears/2009/08 /07/electric-car-charge-stations-next-third-space

[5] ERSE - Entidade Reguladores dos Serviços Energéticos, www.erse.pt

[6] "2010 Nissan Leaf electric car: In person, in depth - and U.S. bound", Aug 1st 2009, http://www.autoblog.com/2009/08/01/2010-nissan-leaf-electriccar-in-person-in-depth-and-u-s-b/

[7] Renault Portugal, www.renault.pt 